The Authority's reactor research programme is further described in a separate chapter of the report. A substantial amount of work is still being done on the graphite-moderated gas-cooled reactors being designed by industry for the Central Electricity Authority, and several loops have been built to study the corrosion of carbon steels and stainless steols under the conditions likely to be experienced in pressurized-water reactors, while the use of organic liquids such as diphenyl and terphenyl as alternative to the water moderator and coolant is being investigated. Reactor physics and metallurgical and engineering investigations are being carried out on the alternative reactor using graphite as a moderator and liquid sodium as coolant. In addition to the organic system just mentioned, four other reactor systems are being examined for attaining a much higher fuel-utilization by breeding : the fast reactor system; the homogeneous aqueous reactor system, which attempts to achieve breeding in the uranium233-thorium system, with very low fuel costs; the liquid-metal fuelled reactor system, using a graphite moderator and enriched uranium dissolved in a liquid metal ; and the high-temperature gas-cooled. reactor system. Treatment of irradiated uranium by solution in acid and extraction with organic solvents continued to be a successful method for separating plutonium and recovering uranium for re-use on the industrial scale, and pilot-plant experience has been gained of the process for the extraction of uranium233 from irradiated thorium. Work on the production of a controlled thermonuclear reactor, in which the two main problems to be solved are to bring a mixture of the light elements to a temperature in the region of 100 million deg. C., and to maintain this long enough for the energy released in nuclear fusion to exceed that required to heat the fuel, is still in the laboratory stage.

Besides occupational health problems, the Authority pays much attention to those of waste disposal, in- cluding measures to ensure full protection of the public from possible exposure to radioactive materials. Sales of radioactive isotopes steadily increased, totalling $£ 483,000$, rather more than half of which was for export; the number of consignments was 22,378 compared with 18,835 in 1954-55. The potential uses of radioactive by-products in industry is being actively explored by the Technological Irradiation Group of the Isotope Division, working in close co-operation with industry, and the biological application of irradiation in sterilization and mutation is being actively studied. Antibiotics which are normally destroyed by heat sterilization can be completely freed from bacteriological contamination by simple irradiation. Some 15,000 curies of cobalt- 60 have been made and loaded into machines for cancer teletherapy and for industrial irradiation. Among new applications of radioactive isotopes may be mentioned the use of ammonium phosphate containing radioactive phosphorus to investigate the pollution of beaches by sewage; and the use of weak radioactive solutions to detect leaks in water mains and oil pipe-lines up to twenty miles in length.

During the year, 167 students attended the normal four-week course in the Isotope School and 104 attended special courses. The Reactor School at Harwell throughout the year gave training to staff from industrial firms on the construction and operation of nuclear reactors; and while the export of nuclear reactors will be the responsibility of industry, it will fall to the Authority to provide the necessary fuel elements. The Authority expects to be able to provide natural uranium fuel elements to match whatever volume of export business is secured in the foreseeable future. Up to the present, twenty. two licences have been granted to United Kingdom firms to use inventions owned by the Authority, three to United States firms, one to a firm in West Germany and one to a firm in France.

\title{
EFFECTS OF ATMOSPHERIC POLLUTION IN FORESTRY
}

D URING the recent Sheffield meeting of the British Association, the-morning session on September 4 of Section $K^{*}$ (Forestry) was devoted to four papers on "Forestry in Industrial Areas, with special reference to Smoke Pollution".

Mr. E. M. Conder (Forestry Commaission), in a contribution on "Some Problems of Private Forestry in the Industrial Areas", pointed out that air pollution is not the sole cause of the lack of satisfactory coniferous tree growth in the immediate vicinity of large industrial cities, for fire and theft are also responsible in some measure. From experience in Lancashire, the Black Country, the Nottinghamshire coalfield, and parts of South Yorkshire, he considers sycamore, beech, elm and poplar the most successful timber-producing hardwood species, with other generally resistant but subsidiary species as follow : horse chestnut, birch, holly, rowan, whitebeam, common alder. Only the black pines (with particular emphasis on the Austrian variety) and, in certain circumstances, Japanese larch, can be recommended among the conifers. Besides these there are few species to suggest, apart from monkey puzzle, yew and perhaps the cedars and Lawson's cypress. Trials with Pinus contorta are as yet too young to provide conclusive material and, while Scots pine may be vigorous initially, subsequent development is poor. Mr. Conder suggested that, in high valleys and on hill slopes, trapping of injurious gases by prevalent low cloud may explain the serious effects at these sites. It was emphasized that in surveying pollution effects, attention must always be paid to the fertility of the soil and, among climatic factors, to the influences, in particular, of elevation and exposure.

Atmospheric pollution effects in Yorkshire were discussed by Mr. A. J. Grayson (Forestry Commission), who suggested that though pollution as generally viewed is deleterious, it may imply useful additions to the existing natural 'chemical climate' before the concentration of individual pollutants or combinations gives rise to injury. Historical evidence shows something of the extent to which changes of species in plantations are to be ascribed to the effect of coal-smoke pollution during the past century. However, the elucidation of the factors bringing about deterioration and even death is difficult since the production of smoke is matched by an increased need for timber, leading to preferential cutting, is 
well as, more recently, preferential selection of species. A physical basis of measurement of some of the common pollutants is desirable only in so far as biological assays are hedged with difficulties as to interpretation.

The stimulus for the investigation of country levels of pollution is provided by the need to afforest difficult sites on both sides of the Pennines on inhospitable soils exposed to a dull and harsh climate, where the choice of economic species is in any case restricted. The disentangling of pollution/ exposure and pollution/fertility interactions (if either be possible) is the prime need. In the first place, Forestry Commission research has begun with the assessment of sulphur dioxide by the lead peroxide method. Similar levels indicated by this technique give no assurance that solid deposits will follow similar trends, and the variation in the ratio of water-soluble to insoluble matter collected in deposit gauges indicates the wide range of types of emission, as well as of the history of that emission. The disadvantages of the lead peroxide method may be in its manner of integration, so that in the absence of other observations a particularly highly concentrated visitation at a time of high plant susceptibility may pass undetected.

More fundamental is the question of the effect of prevalent high wind velocities on the rate of forma. tion of sulphate. Two examples, one of moor top as opposed to valley stations in open country, the other of a gauge sheltered by a wood and contrasted with gauges on either side of the wood, suggest discrepancies which may not in fact reflect true differences of sulphur dioxide concentration. Fumigation experiments with sulphur dioxide, often of short duration, have usually been carried out in the past with concentrations of 1-100 times those averaged over a month occurring naturally, though occasionally concentrations in Nature may increase to the higher levels used in fumigation experiments. Mr. Grayson suggested that apart from species (and possibly strain), concentration, and period of fumigation, different ages of plant or plant organs should be treated in fumigation experiments, since fieldobservation suggests that atmospheric pollution effects are often most noticeable in trees after the grand period of height growth is finished.

A paper prepared by Dr. G. Scurfield (at present with the Commonwealth Scientific and Industrial Research Organization, Canberra) was read by the chairman, Mr. M. V. Laurie. Dr. Scurfield began by asking three questions: (i) Is there unequivocal proof that pollution effects are operating to reduce timber yield on certain sites ? (ii) Given such sites, can we designate the pollutants causing the reduction in yield and, if so, can we define an upper permissible limit of concentration for the pollutants concerned ? (iii) Given such pollutants, in what ways do they interfere with the developmental processes of the tree so as to cause a reduction in yield ?

Observations of decline in vigour of tree growth from cities tend to support the contention that the effects of general pollution are cumulative and need not be accompanied by the production of visible leaf lesions. Many such observations are concerned with effects produced by 'general' atmospheric pollution. after the contaminants have undergone considerable dilution and probably interaction. The effects produced by temporary and usually local increases are more certain, and have in a number of cases been checked by means of fumigation experiments. Field- symptoms have been also duplicated in experiments with hydrogen fluoride where this agent has been suspected.

The different levels of pollution which evergreen and deciduous species have to endure are brought out in the typical annual sine curve of sulphur dioxide and smoke (which is of great chemical complexity, but which contains a number of other contaminants) in the vicinity of urban areas. The cumulative effect of a number of pollution cycles is probably to reduce growth indirectly by accelerating leaf abscission. Experiments to determine tolerances in known environmental conditions might be carried out on the following bases: (i) using transplants in the same soil but different pollution regimes, alongside meteorological stations so that any microclimatic differences between sites could be assessed; indicator species (for which damage symptoms for specific pollutants have already been assessed) might also be included ; (ii) using growth chambers through which 'screened' air could be passed, so that specific agents responsible for reduction in growth would eventually be determined. Lastly, by using 'phytotron' techniques, tolerances to combinations of the variables might be determined. Such techniques could also be used to assess the indirect effect on soil fertility.

In answer to the second question posed, Dr. Scurfield emphasized how necessary it is to avoid the tendency to regard sulphur dioxide as the sole gaseous pollutant. In addition to thirty gases listed by the Alkali, etc., Works Registration Act, 1906, recent analyses have shown hitherto unsuspected contaminants. Further, there are the chemical or physical processes occurring after emission; for example, the reaction products of ozone and certain hydrocarbons. Radioactive isotopes, also, should not be ignored altogether. The permissible concentrations allowed to pass to the air are, so far as sylviculture is concerned, largely arbitrary. Upper limits of tolerance will wait on results through the species' ontogeny and under known conditions. When these are known, concentration limits must be reassessed in relation to topography and atmospheric conditions. Where inversions are liable to occur, for example, the ideal solution would be the regulation of rates of emission in accordance with the diffusing properties of the atmosphere at the time. Thus thorough evaluation of sites from a meteorological and atmospheric pollution point of view should preferably be undertaken before planting.

Thirdly, with regard to the physiological processes concerned, it may be said that the most prominent effect of 'general pollution' is to cause premature leaf abscission. Organic sulphur compounds may play some part in these phenomena. Though abscission may not always be due to the same agent, some mitigation might be obtained by treatment with compounds so affecting auxin activity as to retard abscission. Effective elimination of harmful sources will only be undertaken, said Dr. Scurfield, if we emphasize the effects and if we can point to the agents responsible.

Finally, Dr. P. F. Wareing (University of Manchester), who explained that he was in part deputizing for Dr. J. K. A. Bleasdale, whose thesis on the decline of certain leys in the hill pastures of East Lancashire had shown valuable results, and for Dr. Scurfield, who had also worked at Manchester, proceeded to amplify and clarify many of the points mentioned in previous papers. In discussing what is the important 
pollution factor, he pointed out that while good grounds exist for considering sulphur dioxide the main injurious agent, we have not yet determined that some of the accompanying products of coal combustion may not bring about injuries, such as have been described for pollutants resulting from the combustion of petroleum in Los Angeles. The work on fumigation with sulphur dioxide in greenhouse experiments involves only relatively short-term experiments at high concentrations. This provides no real simulation of the processes occurring in Nature. Dr. Wareing also stressed the fact that the most susceptible parts of plants are the leaves, so that evergreens, which retain their leaves during the winter when pollution is usually at the highest levels, are generally less resistant than deciduous species. Nevertheless, other factors must be of importance, since there are marked differences as between different species both among evergreen and deciduous plants.

Further elucidation was provided by Dr. Wareing in the discussion which followed. Mr. M. V. Edwards
(Forestry Commission) brought matters down to earth in referring to the effects visible on some of the high upland plantations. Here similar symptoms of damage are noticeable on young trees where they are seriously exposed to 'clean' winds and those exposed on the South Pennines to smoke-laden winds. The design of experiments required to isolate the factors of pollution and exposure meets with very serious difficulties. The provision of shelter, for example, automatically means the bringing into existence of a different pollution regime. Mr. A. Bleasdale (Meteorological Office) said that if foresters working in this field need help from meteorologists, then they should be as detailed as possible in stating their requirements so that records could be used most effectively.

Both this discussion and the papers point to the great need for study of the cumulative effects in sylviculture of pollution, in addition to the determination of the toxic concentrations of individual contaminants and combinations of pollutants under known conditions.
A. J. Grayson

\section{RESPIRATORY PIGMENTS}

$I^{N}$ $\mathrm{N}$ opening a discussion on "Respiratory Pigments" arranged by Sections D (Zoology), H (Anthropology) and I (Physiology) at the Sheffield meeting of the British Association, Prof. F. J. W. Roughton reminded his audience that eight years had passed since the Barcroft Memorial Conference on hæmoglobin had met at Cambridge, and said that they had been years of rapid progress, some of it stimulated by that Conference. In the discussion three groups interested in hæmoglobin were all represented : they were physiologists, who are concerned with its role in promoting gas exchanges in the animal body, biochemists interested in the mechanism and physical chemistry of the gas reactions, and biophysicists who find it an easily available and readily crystallized material already carefully studied and characterized physiologically.

The first paper, by Profs. Q. H. Gibson and F. J. W. Roughton, was concerned with the thoroughgoing application of Adair's intermediate-compound hypothesis to the equilibria, and kinetics of the reactions of hæmoglobin with gases. Adair's original paper, published thirty-one years ago, suggested that combination of each hæmoglobin molecule with four molecules of gas takes place in four distinct stages, one gas molecule combining at a time to yield separate molecular species containing one, two, three or four gas molecules.

The general acceptance of Adair's hypothesis has been delayed by the failure of attempts to demonstrate the intermediate compounds spectroscopically, and because the equation giving the relation between oxygen tension and percentage saturation arising from the intermediate-compound hypothesis contains four constants-enough to allow any ordinary experimental equilibrium curve to be fitted within $0 \cdot 5-1$ per cent saturation by several sets of constants with widely differing values.

In recent years, Roughton and his co-workers at Cambridge have overcome the second difficulty by refining the methods used for determining the dissociation curve and extending them to the ranges 0-1 per cent and 98-100 per cent saturation, so that only one set of constants can be found to fit the experimental results. This work has shown that, for sheep hæmoglobin, there is a great increase in affinity for oxygen after three molecules have combined, the affinity for the fourth molecule being, at $p \mathrm{H} 9 \cdot 1$, 280 times greater than that for the first.

The kinetic work described in the same paper is an example of co-operative research carried on by several groups of workers. The problem was to determine numerical values of the four combination velocity constants for the reaction of reduced hæmoglobin with carbon monoxide. The experimental material, records of the change in concentration of reduced hæmoglobin with time, was obtained by the stopped-flow photo-electronic method, in Sheffield. The percentage saturation was found to within $0 \cdot 5$ per cent during the period from 5 to 100 msec. after bringing the reactants together, using a photomultiplier and cathode-ray oscillograph to follow the reaction. The results were then compared, by Dr. H. E. Daniels, of the Cambridge Statistical Laboratory, with solutions of the differential equations describing the reaction. These solutions were computed by the EDSAC electronic machine in the Cambridge Mathematical Laboratory. In this way the values of the individual velocity constants for the combination of successive carbon monoxide molecules were found, together with their standard errors. Here again, with sheep hæmoglobin at $p \mathrm{H} 9 \cdot 1$, it was found that a great increase in combination velocity took place after three molecules of carbon monoxide had combined, the fourth molecule combining some sixty to eighty times faster than the first.

Although the new results have allowed the unequivocal application of the intermediate-compound hypothesis to one kinetic case, much remains to be done, especially to extend the analysis to the physiologically interesting case of combination with oxygen, though the formidable difficulties of reckoning with eight independent kinetic constants may well delay a solution for some time.

Dr. V. M. Ingram followed with an account of recent progress in research on the structure of hæmo- 